\title{
An update on the performance of STI services for gay and bisexual men across European cities: results from the 2017 European MSM Internet Survey
}

\author{
Jason Doran (1) , ${ }^{1}$ Peter Weatherburn, ${ }^{1}$ Ford Hickson, ${ }^{1}$ Ulrich Marcus, ${ }^{2}$ David Reid, ${ }^{1}$ \\ Axel Jeremias Schmidt (i) ${ }^{1}$
}

${ }^{1}$ Sigma Research, Department of Public Health, Environments and Society, London School of Hygiene and Tropical Medicine Faculty of Public Health and Policy, London, UK

Department of Infectious Diseases Epidemiology, Robert Koch Institut, Berlin, Germany

Correspondence to Dr Axel Jeremias Schmidt, Sigma Research, Department of Social \& Environmental Health Research, London School of Hygiene and Tropical Medicine Faculty of Public Health and Policy, London WC1H 9SH, UK; axel.j.schmidt@emis-project.eu

Received 26 June 2020 Revised 15 September 2020 Accepted 17 September 2020 Published Online First 3 November 2020

Check for updates

(C) Author(s) (or their employer(s)) 2021. No commercial re-use. See rights and permissions. Published by BMJ.

To cite: Doran J Weatherburn P, Hickson F et al. Sex Transm Infect 2021:97:201-208

\section{ABSTRACT}

Objectives Rectal STIs compromise health and are common in men who have sex with men (MSM). However, the European-MSM-Internet-Survey (EMIS2010) showed that in 2010, the prevalence of anal swabbing during STI screening by MSM varied widely across 40 European cities. In this paper, we replicate a variety of measures of STI testing performance using 2017-18 data and extending the geographic spread of the analysis.

Methods Data were analysed from the EMIS-2017, a 33-language online sexual health survey accessible from 18 October 2017 to 31 January 2018. We focus on a subsample of 38439 respondents living in the same 40 European cities we reported on in 2010. For a broader perspective, we also included an additional 65 cities in the analysis (combined $n=56$ 661). We compared the prevalence of STI screening in MSM and disclosure of same-sex sexual contacts to the healthcare provider. We applied multivariable logistic regression models to compare the odds of MSM receiving each of four diagnostic procedures, including anal swabbing in the previous 12 months, controlling for age, HIV diagnosis, pre-exposure prophylaxis use and number of sexual partners.

Results In 2017, across 40 European cities, the proportion of respondents screened for STIs ranged from under $19 \%$ in Belgrade to over $59 \%$ in London. At an individual level, in comparison to London, the adjusted $\mathrm{OR}$ (AOR) of having received anal swabbing ranged from 0.03 in Belgrade, Bucharest and Istanbul to 0.80 in Oslo, with little evidence for a difference in Amsterdam and Dublin. Since 2010, most cities in West and South-west Europe have substantially narrowed their performance gap with London, but some in East and South-east Europe have seen the gap increase.

Conclusions Although comprehensive STI screening in MSM has expanded across many European cities, the low prevalence of anal swabbing indicates that rectal STIs continue to be underdiagnosed, particularly in East/ South-east Europe.

\section{INTRODUCTION}

Underdiagnosis of STIs in men who have sex with men (MSM) compromises the health of men infected, exposes their partners to infection and-in the absence of condoms or pre-exposure prophylaxis (PrEP)-increases the risk of HIV transmission for both parties. ${ }^{1-3}$

Early detection strategies prioritise the screening of individuals with multiple/concurrent sexual partners. Comprehensive screening includes specimen collection tailored to sexual practices and physical examination of the genitals, anus and oropharynx. $^{4}$

However, data from the 2010 European-MSMInternet-Survey (EMIS-2010) demonstrated that in most European cities, screenings for STIs among MSM did not include anal swabbing or anogenital inspection, ${ }^{5}$ suggesting substantial underdiagnosis of rectal gonorrhoeal/chlamydial infections and anogenital warts.

Diagnostic services and healthcare provision for STIs are not uniform across Europe. ${ }^{6}$ Such services can be delivered in private practices, genitourinary medicine clinics, specialised STI services within hospitals, dermatology clinics, municipal health offices and in gay health centres (typically called 'checkpoints' in continental Europe). There is wide variation in the diagnostic procedures recommended and used, and how much clients have to pay for an STI screen. ${ }^{78}$ There has also been a recent move towards clients self-sampling and posting specimens with results returned by text or online.

EMIS was repeated in $2017-18 .^{10}$ In this paper, we compare the performance and components of STI screening and services used by MSM across the same 40 cities we studied in $2010 .^{5}$ We also report data collected from 65 additional cities across Europe, Canada, Lebanon, Israel and the Philippines.

\section{METHODS}

The detailed methods of EMIS have been reported elsewhere. $^{11} 12$ In summary, EMIS-2017 was a 33-language, internet-based, self-completion cross-sectional survey for MSM and/or are sexually attracted to other men. EMIS-2017 was live and collected data from 50 countries between 18 October 2017 and 31 January 2018. In addition to the participating European countries in 2010, in 2017, a small number of non-European countries (Canada, Israel, Lebanon and the Philippines) joined the survey. 


\section{Recruitment}

Recruitment occurred in 50 countries, through transnational dating apps (PlanetRomeo, Grindr and Hornet accounted for 68\% of recruits; Qruiser, RECON, SCRUFF, Gaydar, Manhunt/ Jack'd, GROWLr and Bluesystem for another 9\%), through national partners via websites (10\% of recruits) and social media (7\%). Typical completion time was $20 \mathrm{~min}$. No financial incentives were given to participants. No personal identifying information (including IP addresses) were collected. More background information is available at www.emis2017.eu.

\section{Measures}

The questionnaire was designed to measure, among other things, the coverage of HIV/STI prevention interventions specifically targeting MSM, including screening. All participants were asked when they last had 'a test for STIs other than HIV'. Those who had tested in the previous 12 months were asked about the presence or absence of symptoms at their last STI test. STI screening was defined as the last STI test being in the absence of symptoms. To understand whether healthcare providers knew their male clients had sex with men, disclosure of same-sex sexual contacts was defined as respondents who reported that the healthcare provider during their last STI test 'definitely knew' that they had sex with men. Respondents tested for STIs in the previous 12 months were also asked which of the following six diagnostic procedures were used: blood test, urine sample, genital swab, genital inspection, anal swab, anal inspection. Questions were phrased in plain language to avoid specialist medical terms. As the gender identity group 'men' includes people whose sex assigned at birth could be male or female, we inserted the following routing question prior to those on diagnostic procedures: "So we can ask appropriate questions about STItests, and because people's bodies differ, do you have: a penis (cock), a vagina (pussy, front-bottom); both of these; neither of these". The six procedures were collapsed into four: blood test was defined as having 'provided a blood sample'; genital test as having 'provided a urine sample' or 'something inserted into your penis/vagina'; inspection as as having had 'your penis/ vagina' and 'your anus examined' and anal swab as having had 'something inserted into your anus (anal swab)'.

\section{Statistical analysis}

We compared the prevalence of STI screening in MSM and disclosure of same-sex sexual contacts towards the healthcare provider. To compare across cities the odds of undergoing the four procedures (blood test, genital test, inspection and anal swab), we applied four individual-level multivariable logistic regression analyses using SPSS (V.26, IBM, New York, USA) with stepwise inclusion of variables, controlling for the a priori confounders of age $(<25 ; 25-39 ; \geq 40)$ and HIV diagnosis. As some countries had implemented PrEP by late 2017, and as PrEP users-like MSM with diagnosed HIV-typically enter a clinical routine and therefore are more likely to be monitored for STIs, we further controlled for PrEP use by grouping respondents into three categories: diagnosed HIV, current PrEP use, neither. As with the EMIS-2010 data, we also controlled for the overall number of sexual partners in the previous 12 months $(0 ; 1 ; 2-5$; $6-10 ;>10)$ to ensure that the differences in intervention performance observed between cities were not confounded by differences in partner numbers in the respective subsamples. The last control variable included was any discrepancy in major variables (eg, age), to ensure our results are not confounded by survey respondents answering randomly. In recognition that STI testing in many countries is organised at a subnational level, we chose cities and not countries as units of comparison in the multivariable logistic regressions. We chose London as reference to replicate the previous study, and due to its subsample size and high level of screening. European cities were defined by self-reported postal code/subregion of residence, combined with settlement size. The same 40 large ( $\geq 500000$ inhabitants) European cities or country capitals as in 2010 were included in the narrative. However, using data from 2017, we provide the same measures on 65 additional cities across Europe, Canada, Lebanon, Israel and the Philippines in an online supplemental table S1.

\section{RESULTS}

\section{Respondents}

The online supplemental table S1 includes data from 56661 respondents living in 105 cities-43.3\% of the entire EMIS2017 sample ( $n=137$ 358). For comparability purposes, the narrative focuses on the 38439 respondents living in the 40 European cities from 2010, shown in table $1-28 \%$ of the entire sample. At the time of the survey, all respondents, identified as men, were above the age of sexual consent in the country they lived in; and had sex with and/or were sexually attracted to men. Excluded from this analysis were: 6543 respondents (4.8\%) living in large ( $\geq 500000$ inhabitants) cities or country capitals that did not reach the minimum city-sample size of 100; 64638 (47.1\%) who lived in smaller cities (not country capitals) and $9516(6.9 \%)$ who declined to say where they lived. Across the city MSM samples, there was substantial variation in age, diagnosed HIV, PrEP use and numbers of sexual partners (table 1, online supplemental table S1).

\section{STI screening and diagnostic procedures}

STI screening in the previous 12 months ranged from $19 \%$ in Belgrade to 59\% in London (city median 43\%, IQR: 38\%-49\%). Among those screened, the most common diagnostic procedure in all cities was a blood test (city median 94\%, IQR: 92\%-96\%). Genital tests (urethral swab or urine sample) were less common (median 61\%, IQR: 43\%-75\%), ranging from 33\% in Ljubljana to $96 \%$ in Birmingham. The city median for the proportion of screens that included an anal swab was 29\% (IQR: 15\%-49\%) and varied from 6\% in Bucharest up to $86 \%$ in Amsterdam. The city median reporting an inspection of the anus and genitals was $13 \%$ and varied from $4 \%$ in Warsaw to $32 \%$ in Helsinki (IQR: 10\%-19\%) (table 1, online supplemental table S1).

\section{Disclosure of having sex with men}

In most cities, respondents reported high levels of disclosing having sex with men to their healthcare provider when being screened for STIs. Disclosure ranged widely from 94\% in London to $17 \%$ in Moscow, with a median of $73 \%$ (IQR: $56 \%-88 \%$ ). Disclosure was above $87 \%$ in Amsterdam, Berlin, Birmingham, Copenhagen, Dublin, London, Manchester, Oslo, Stockholm and Zurich (table 1, online supplemental table S1). Figure 1 illustrates how the adjusted OR (AOR) for receiving anal swabbing was positively associated with disclosure at city level.

\section{Multivariable logistic regression}

In multivariable logistic regression analyses, the AOR for receiving the four diagnostic procedures among all respondents living in the same city increased steadily with the number of sexual partners and was up to four times higher for respondents diagnosed with HIV, and up to nine times higher for respondents using PrEP. When compared with men aged 25-39 years, 


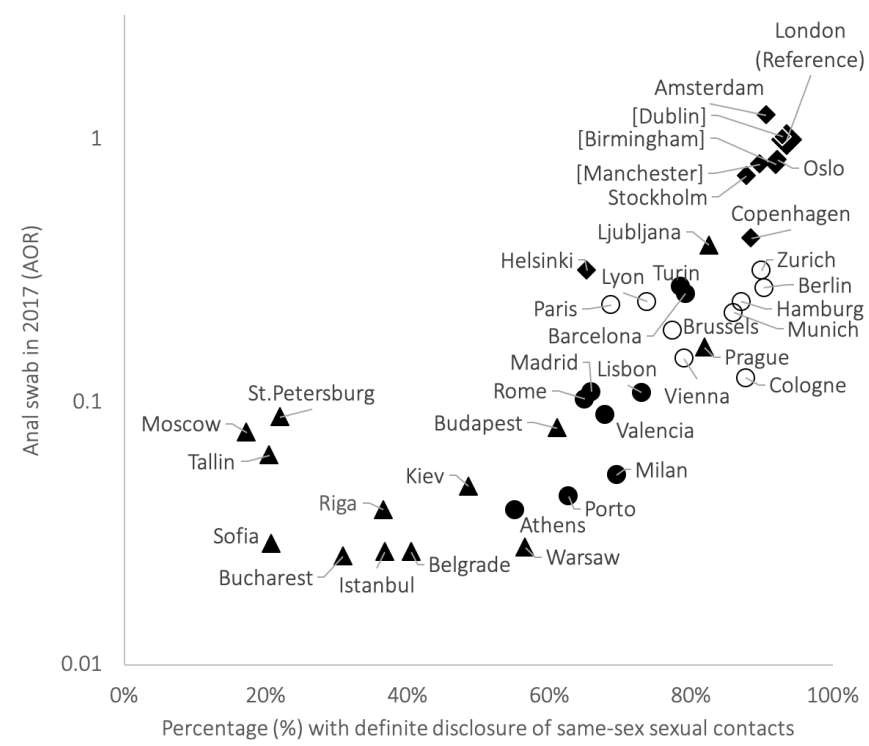

Figure 1 Scatterplot of the adjusted Odds Ratio (AOR) for receiving anal swabbing in the previous 12 months, relative to London, versus disclosure of same-sex sexual contacts, comparing 40 European cities in European-MSM-Internet-Survey-2017. Black diamond, North-west Europe (including the Netherlands and the UK); open circle, West Europe; black circle, South Europe; black triangle, East and South-east Europe, [p $>0.05$ on $y$-axis].

younger and older men were less likely to report any of the four procedures (online supplemental table S1).

\section{Blood test}

The AOR of receiving a blood test did not differ greatly between Amsterdam and London (table 1, online supplemental table S1). In all other cities, respondents were less likely to have received a blood test compared with respondents in London (median $\mathrm{AOR}=0.54$ ) with a blood test being least common in Belgrade $(\mathrm{AOR}=0.17)$.

\section{Genital test}

As with blood tests, minimal differences in the AOR were observed between London and Amsterdam for respondents receiving a genital test. In all other cities, respondents were less likely to have received a genital test (median $\mathrm{AOR}=0.25$ ), with a genital test being least common in Belgrade ( $\mathrm{AOR}=0.06)$.

\section{Inspection}

In Dublin, respondents were almost twice as likely to have their genitals/anus inspected than in London (AOR $=1.99)$. The AOR for receiving a genital/anal inspection were also higher in Amsterdam, Berlin, Birmingham, Copenhagen, Helsinki, Manchester, St. Petersburg, Stockholm and Turin, compared with London. In all other cities, respondents were less likely to have received a genital/anal inspection (median $\mathrm{AOR}=0.65$ ) than in London, with a genital/anal inspection least likely to be received in Warsaw $(\mathrm{AOR}=0.18)$.

\section{Anal swab}

The AOR of MSM receiving an anal swab was significantly higher in Amsterdam than compared with London ( $\mathrm{AOR}=1.24)$. In Birmingham, Manchester and Dublin there was no significant 

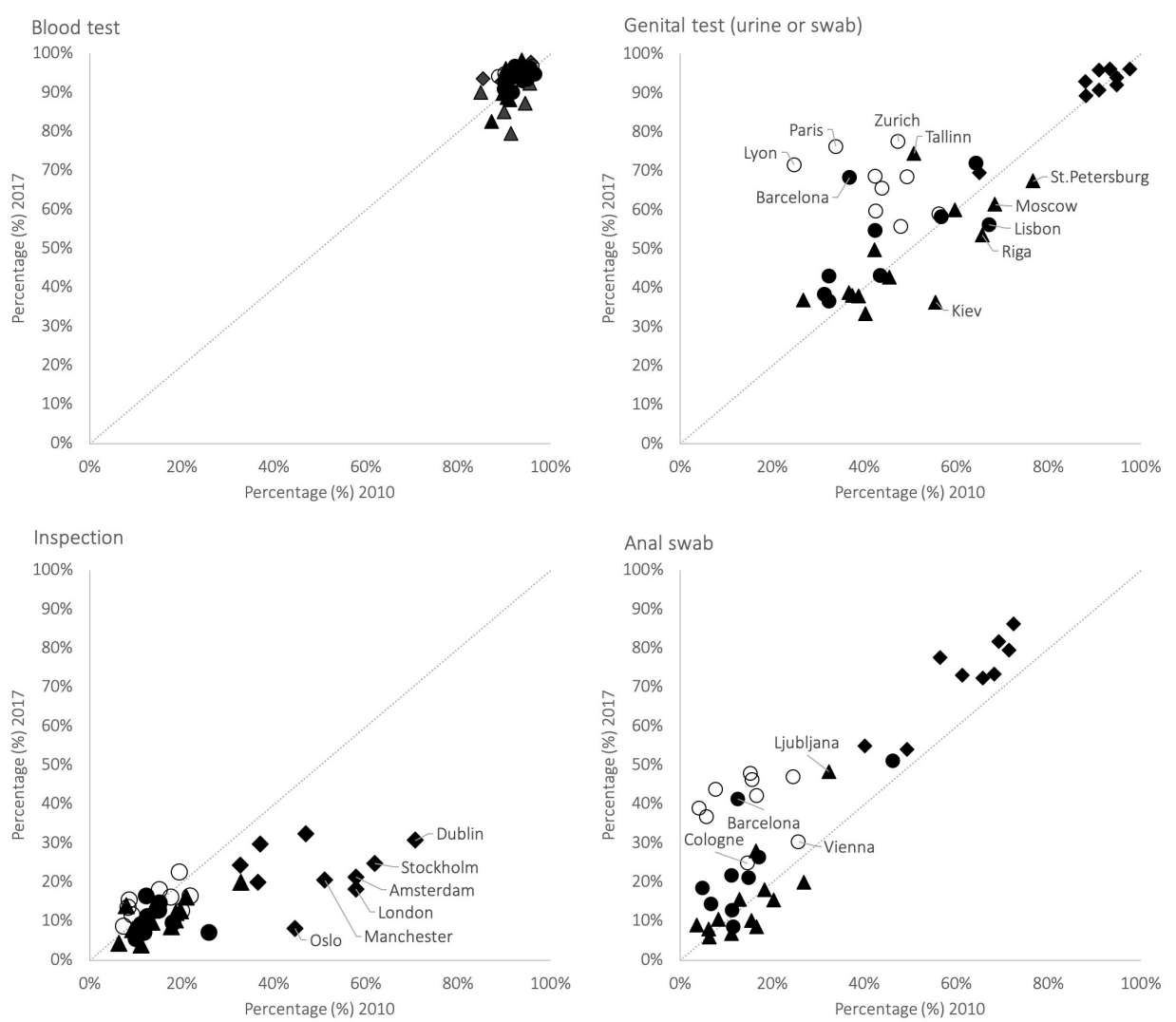

Figure 2 Scatterplots of the proportions of four diagnostic procedures during STI screening in the previous 12 months across 40 European cities in the European-MSM-Internet-Survey (EMIS)-2017 vs EMIS-2010. Black diamond, North-west Europe (including the Netherlands and the UK); open circle, West Europe; black circle, South Europe; black triangle, East and South-east Europe.

difference. In all other cities, MSM were less likely to have received anal swabbing (median $\mathrm{AOR}=0.15$ ), with having an anal swab being least common in Belgrade, Bucharest and Istanbul (AOR=0.03).

In summary, offering anal swabs for the detection of rectal bacterial STIs was highest in UK cities, Dublin, Amsterdam, Oslo and Stockholm.

\section{Comparison with EMIS-2010}

Reporting recent STI screening increased between 2010 and 2017 among MSM in all cities except Belgrade. In comparison with 2010, among MSM screened for STIs, the percentage receiving a blood test was high and relatively stable. In 2017, there was also an increase in the percentage of MSM receiving a genital test in 27 cities, with a decrease in 13 (Birmingham, Bucharest, Helsinki, Kiev, Lisbon, Ljubljana, Manchester, Moscow, Riga, Rome, St. Petersburg, Stockholm and Warsaw). The percentage of MSM receiving an inspection increased in only 8 cities since 2010 (Barcelona, Belgrade, Berlin, Brussels, Lyon, Munich, Paris and Valencia) but decreased in 32. In contrast, the percentage of MSM receiving an anal swab increased in 32 cities and decreased in 8 (Athens, Bucharest, Kiev, Moscow, Riga, Sofia, St. Petersburg and Tallinn). Visual representations of these changes can be seen in figure 2, where cities below the diagonal line represent a decrease in proportions since 2010, while cities above the line represent an increase. The change of the odds for anal swabbing is shown in figure 3 .

At city level in 2010, AORs for having received an anal swab and for having had an anal and genital inspection showed an almost perfect correlation $\left(\mathrm{R}^{2}=94.3 \%\right)$. In 2017 , this association was much lower $\left(\mathrm{R}^{2}=54.9 \%\right)$ - mostly due to a differential in decreasing inspections in North-west Europe and increasing anal swabbing in West Europe.

\section{DISCUSSION}

Our two large, anonymous online surveys suggest that STI screening among MSM has substantially increased between 2010 and 2017/18 in many European cities. The components used in STI screening also show a profound change, with increases in urine samples and anal swabbing. These changes may partly explain the rise in STI diagnoses across Europe. ${ }^{13}$ Comprehensive and accessible diagnostic services, where men feel comfortable disclosing same-sex sexual contacts, are essential to increase early detection of STIs. Our findings reflect a move towards a more client-focused MSM healthcare since 2010 across many of these 40 European cities, but change is not universal and we see widening inequity between cities as a consequence.

In 2017, reported STI screening rates substantially increased from 2010 but continued to vary considerably by city. These findings suggest changes in testing policies and/or increase of provision and/or uptake of current services. Furthermore, an increase in MSM-targeted diagnostic services (eg, 'checkpoints') has occurred in many European countries which may be responsible for increased genital testing and anal swabbing among MSM. $^{7}$

To ensure early diagnosis and treatment in MSM, screening of STIs must include a combination of blood tests, genital tests and anal swabbing. ${ }^{14}$ Anal swabs rather than solely urine samples (or urethral/meatal swabs) are necessary for the detection of asymptomatic gonorrhoea or chlamydia, not least because rectal infections last longer than infections at other sites. ${ }^{16}$ 


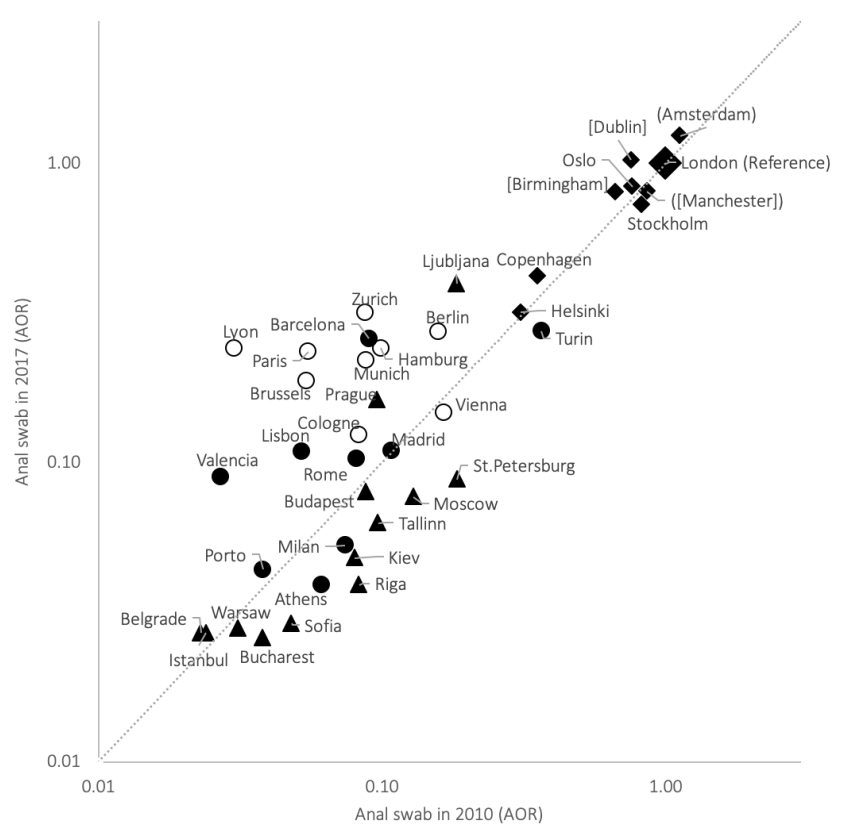

Figure 3 Scatterplot of the adjusted Odds Ratio (AOR) for receiving anal swabbing in the previous 12 months, relative to London, comparing 40 European cities in the European-MSM-Internet-Survey (EMIS)2017 vs EMIS-2010. Black diamond, North-west Europe (including the Netherlands and the UK); open circle, West Europe; black circle, South Europe; black triangle, East and South-east Europe, [ $p>0.05$ on $y$-axis], ( $p>0.05$ on $x$-axis).

Similar to 2010, we found that an STI screen almost universally included a blood test. It is therefore likely that STIs which are diagnosed using blood-based tests, such as syphilis, are more readily diagnosed than STIs which require more costly testing procedures, such as nucleic acid amplification tests for the detection of Neisseria gonorrhoeae or Chlamydia trachomatis. The proportion of respondents who reported having their anus swabbed during their last STI test has increased since 2010 across most of the 40 cities. Conversely, the proportion who reported having anogenital inspection has decreased considerably from 2010. The advent of self-testing/swabbing may provide the answer to this disparity. In the UK and elsewhere, an increasing number of clinics allow clients to perform their own rectal and pharyngeal swab. While this increases efficiency and comfort to the users, it does not provide any opportunity for a healthcare professional to inspect the anus and genitals. In some countries, there is a growing number of internet/online self-sampling kits being ordered. ${ }^{17}$ This trend could further reduce the number of inspections during screening. While the increased rates of anal swabbing can potentially increase the diagnosis of rectal gonorrhoea and chlamydia, the large decrease in inspection may perpetuate the underdiagnosis of anogenital warts and early forms of anal cancer, ${ }^{18}$ particularly in the absence of widespread HPV vaccination among MSM. ${ }^{19}$

Compared with MSM with diagnosed HIV, MSM using PrEP had twice the odds of having received a blood or genital STI test and almost three times the odds for anal swabbing, with no significant difference for anogenital inspection. These findings reflect the rigorous standards for 3-monthly triple-site swabbing in most PrEP guidelines, ${ }^{20}$ and the difficulties seen in some clinics with respect to the implementation of comparable clinical follow-up ${ }^{21}$ for people living with HIV, or the absence of specific STI screening recommendations in European clinical HIV guidelines. ${ }^{22}$

This study found disclosure of same-sex activity to be high in the majority of cities, with a city median disclosure rate of over $80 \%$. However, disclosure remained low across East and Southeast Europe. Homophobic climates continue to hinder actions by non-governmental gay, bisexual, trans and HIV/AIDS organisations. Conversely, more homo-socially liberal cities showed higher rates of disclosure. These findings highlight the need for MSM to feel more comfortable 'coming out' to their healthcare provider who could subsequently tailor STI testing procedures according to their sexual practices.

\section{Strengths}

The EMIS questionnaire distinguished STI screening from diagnostic STI testing, and it allows the calculation of rates of STI screening and STI testing with respect to different time frames, for example, ever, the previous 5 years, 12 months (used in this analysis), 6 months or 4 weeks. The questionnaire was also designed for comparing a variety of testing procedures during STI testing in the previous 12 months, or of disclosure of having sex with men at last STI test.

In this analysis, we compared performance of STI testing for MSM between cities, controlling only for variables likely to reflect recruitment biases (age composition, diagnosed HIV or PrEP use, number of sexual partners). MSM populations in different European cities also differ with respect to migration status, sexual identity, being 'out' about sexual orientation, gay community attachment and the degree of legal, societal and institutional homophobia. Although all these variables were significantly associated with the presented outcomes, we did not include them in the regression models, because they would mask the differences between cities. Nevertheless, they all contribute to the degree to which MSM are reached by targeted information and services including their STI transmission knowledge or where and how often to present for STI screening, and the likelihood of disclosing their homosexual activity to healthcare providers. The chosen analytic strategy ensures that observed differences between cities are neither confounded by varying or increasing numbers of sexual partners, nor by the availability of PrEP in some countries.

Our inclusion of 105 cities for this analysis (online supplemental table S1) has several advantages. The observation that cities in the same country provided similar results confirms the validity of our findings and has the potential to inform policy in a large number of cities. It also allows comparisons between cities in countries not covered in the EMIS-2010 analyses.

\section{Limitations}

The self-reported data collected in EMIS-2017 is subject to recall bias (plus an element of social-desirability bias, believed to be negligible in this analysis). The four diagnostic procedures are constructs based on the questions about what was done as part of STI screening; thus, the validity of what is called, for example, a genital test may be questioned. However, our pretesting of the survey in a variety of languages showed that the non-medical language was appropriate and understood by respondents.

Due to the absence of denominator studies and sampling frames, large representative random samples of MSM are impossible to recruit. Two-stage recruitment exploiting existing national probability samples is feasible, ${ }^{23}$ as well as pooling data from multiple studies. ${ }^{24}$ However, the former is costly and time consuming and the latter yields limited variables. We relied on a convenience 
sample. The Law of Large Numbers suggests that for the larger city samples, the range is adequately represented. ${ }^{25}$ The raw proportions for the four diagnostic procedures among those screened (including figure 2) might be affected by differences in sampling across cities and across the two study waves. In order to address such selection bias inherent to all convenience samples, in this update paper as in the previous publication, we adjusted for possible sampling differences across cities. Given that EMIS is a low access-threshold online self-completion survey, some of the data are invalid-however our findings are controlled for inconsistent data, for example, randomly selected answers.

This study cannot answer the question if antibiotic treatment following screening for asymptomatic STIs may impair immune response and thus paradoxically lead to higher rates of some STIs, such as chlamydial infections, ${ }^{26}{ }^{27}$ or increase antimicrobial resistance. Models suggesting a decline in STI incidence following rigorous screening ${ }^{28}$ did not control for this possibility.

\section{CONCLUSIONS}

The majority of the 40 European cities we studied in 2010 have made substantial progress towards more comprehensive STI testing services for MSM, likely contributing to increased diagnoses of gonorrhoea and chlamydia infections, and possibly to interrupting transmission chains. ${ }^{28}$ However, suboptimal conditions for disclosure of same-sex activity and suboptimal testing procedures remain the norm in some cities, particularly in East and South-east Europe.

Key messages

- This study compares STI screening performance specific to men who have sex with men (MSM) across time (2010 vs 2017) and space (105 cities in 39 countries).

- Screening for genital and particularly rectal STIs (such as gonorrhoea/chlamydia) has become much more common.

- Among MSM screened for STIs, syphilis testing has remained almost universal.

- In many European cities, particularly in East and Southeast Europe, disclosure of same-sex activity is limited, undermining tailoring of testing procedures.

Correction notice The article has been corrected since it was published. The captions for Figures 1 and 3 have been updated.

\section{Handling editor Tristan J Barber}

Twitter Jason Doran @JasonRDoran and Peter Weatherburn @sigmaresearch1

Acknowledgements The authors would like to thank all study participants and collaborators for being part of something huge. EMIS-2017 is coordinated by Sigma Research at the London School of Hygiene and Tropical Medicine (LSHTM) in association with the Robert Koch Institute (RKI) in Berlin. The following list acknowledges all partners in EMIS by country. Individual names are mentioned if a freelancer was the main contact and/or translator or where input on the questionnaire development came from a person not formally representing an organisation. The order (if available) is main NGO partner, other NGO partners, academic partners, governmental partners, individuals. Europe: PlanetRomeo, European AIDS Treatment Group (EATG), Eurasian Coalition on Male Health (ECOM), European Centre for Disease Prevention and Control (ECDC), European Monitoring Centre for Drugs \& Drug Addiction (EMCDDA), European Commission (DG SANTE). AL: Arian Boci. AT: Aids Hilfe Wien, Dr Frank M. Amort. BA: Igbti.ba, Masha Durkalić. BE: SENSOA, exaequo, Observatoire du SIDA et des sexualités, Sciensano. BG: HUGE, GLAS Foundation, Dr Emilia Naseva, Petar Tsintsarski. BY: Vstrecha. CA: Health Initiative for Men, Rézo, Gay Men's Sexual Health Alliance of Ontario, CATIE, Ontario HIV Treatment Network, Université du Quebec \& Montréal, University of Toronto, University of Windsor, University of Victoria, Public Health Agency of Canada, Rob Gair. CH: Swiss AIDS Federation, Cantonal Hospital St. Gallen, Centre Hospitalier Universitaire Vaudois, University Hospital Zurich, Swiss Federal Office of Public Health. CY: AIDS Solidarity Movement. CZ: AIDS pomoc, National Institute of Public
Health, Tereza Zvolska, Dr Michal Pitoňák. DE: Deutsche AIDS-Hilfe, Robert Koch Institute, BZgA, Dr Michael Bochow, Dr Richard Lemke. DK: AIDS-Fondet, Statens Serum Institut, François Pinchon, Jakob Haff. EE: Eesti LGBT, VEK LGBT, Estonia National Institute for Health Development, Dr Kristi Rüütel. ES: Stop Sida, CEEISCAT, Ministerio de Sanidad. FI: Positiiviset, Hivpoint, SeksiPertti, Trasek, National Institute for Health and Welfare. FR: AIDES, Coalition PLUS, SexoSafe, Santé Publique France, INSERM. GR: Ath Checkpoint, Thess Checkpoint; Positive Voice. HR: Iskorak, gay. hr, Zoran Dominković, Vjeko Vacek. HU: Háttér Society, Tamás Bereczky. IE: Gay Health Network, Man2Man, HIV Ireland, Outhouse, GOSHH, Sexual Health Centre Cork, AIDSWEST, Gay Community News, Health Service Executive, Gay Men's Health Service, Sexual Health and Crisis Pregnancy Programme, Health Protection Surveillance Centre. IL: Israel AIDS Task Force, Israel Ministry of Health, Dr Zohar Mor. IS: Samtökin'78. IT: Arcigay, Fondazione LILA Milano ONLUS, University of Verona, Dr Raffaele Lelleri. LB: SIDC, Dr Ismaël Maatouk. LT: demetra, LGL, Gayline. LV: Testpunkts, Baltic HIV Association, Dr Antons Mozalevskis, Indra Linina. MD: GENDERDOC-M. ME: Juventas. MK: Subversive Front, Dr Kristefer Stojanovski. MT: Malta LGBTIQ Rights Movement, Allied Rainbow Communities, Infectious Disease Prevention and Control Unit, Silvan Agius, Russel Sammut. NL: Results in Health, Maastricht University, Amsterdam Pink Panel, Soa Aids Nederland, Rutgers, Dr Wim Vanden Berghe, Marije Veenstra. NO: Helseutvalget, Norwegian Directorate of Health, Folkehelseinstituttet, Dr Rigmor C. Berg. PH: Bisdak Pride-Cebu, Cebu Plus, HASH, Pinoy Plus, UP Babaylanes, YPEER, TLF, Office of the WHO Representative in the Philippines, Natasha Montevirgen, Mikael N. Navarro. PL: Spoleczny Komitet ds AIDS, Kampania Przeciw Homofobii, Lambda Warszawa, Dr Łukasz Henszel. PT: GAT Portugal, CheckpointLX, Associação ABRAÇO, rede ex aequo, SexED, dezanove, ILGA Portugal, Trombeta Bath, ISPUP. RO: Association "Eu sunt! Tu?", PSI Romania, ARAS Romania, Tudor Kovacs. RS: Association Duga, Association Red Line, Omladina JAZAS-a Novi Sad, Institute of Public Health of Serbia, Sladjana Baros, Dr Marija Pantelic. RU: The Charity Foundation For Support of Social Initiatives and Public Health/LaSky Project. SE: RFSL, University of Gothenburg, Folkhålsomyndigheten. SI: ŠKUC, Legebitra, LJUDMILA. SK: PRIDE Košice, Light-House Slovakia, Slovak Medical University, Public Health Authority of the Slovak Republic, Dr Zuzana Klocháňová. TR: Pozitif Yaşam, Sami S. Yazııılaroğlu. UA: Alliance for Public Health, alliance. global, msmua.org, Oleksii Shestakovskyi. UK: Terrence Higgins Trust, NAM, PrEPster, Antidote, Horizon Drugs and Alcohol Support, LGBT Foundation, Yorkshire MESMAC MESMAC Newcastle, Derbyshire LGBT+, Trade Sexual Health, London Friend, GMFA, Spectra, International HIV Partnerships, International Planned Parenthood Federation Bristol University, University College London, Sigma Research, Raul Soriano. Other: Dr John Pachankis, Dr Mark Hatzenbühler, Dr Valeria Stuardo Ávila, Dr Michael W. Ross.

Contributors JD performed the statistical analysis and wrote the manuscript. PW, AJS, UM, FH and DR designed EMIS-2017. FH and DR drafted and pretested the questionnaire; AJS co-ordinated the study and the EMIS network, led this paper, supervised the statistical analyses and co-wrote the manuscript. All authors contributed to the manuscript and agreed on the final version.

Funding EMIS-2017 was carried out as part of ESTICOM, under the service contract 20157101 with The Consumers, Health, Agriculture and Food Executive Agency (Chafea), acting under powers delegated by the Commission of the European Union. Other financial contributions were received from: Swedish Ministry of Health for recruitment in the Nordic Countries; The Arctic University of Norway and University Hospital of North Norway for Russia; Israel Ministry of Health for Israel; Public Health Agency of Canada for Canada; Office of the WHO Representative in the Philippines for the Philippines.

Competing interests None declared.

\section{Patient consent for publication Not required.}

Ethics approval EMIS-2017 received a favourable ethical opinion from the Observational Research Ethics Committee at the London School of Hygiene and Tropical Medicine (review reference 14421/RR/8805) on 31 July 2017.

Provenance and peer review Not commissioned; externally peer reviewed.

Data availability statement Data are available on reasonable request. EMIS data are not yet publicly available. For questions on data access, please contact coordinator@emis-project.eu.

\section{ORCID iDs}

Jason Doran http://orcid.org/0000-0002-5501-9433

Axel Jeremias Schmidt http://orcid.org/0000-0002-6910-4399

\section{REFERENCES}

1 Wasserheit JN. Epidemiological synergy. Interrelationships between human immunodeficiency virus infection and other sexually transmitted diseases. Sex Transm Dis 1992;19:61-77.

2 Wasserheit JN, Aral SO. The dynamic topology of sexually transmitted disease epidemics: implications for prevention strategies. J Infect Dis 1996;174 Suppl 2:S201-13. 
3 Chin-Hong PV, Husnik M, Cranston RD, et al. Anal human papillomavirus infection is associated with HIV acquisition in men who have sex with men. AIDS 2009;23:1135-42.

4 Peters RPH, Verweii SP, Nijsten N, et al. Evaluation of sexual history-based screening of anatomic sites for Chlamydia trachomatis and Neisseria gonorrhoeae infection in men having sex with men in routine practice. BMC Infect Dis 2011:11:203.

5 Schmidt AJ, Hickson F, Weatherburn P, et al. Comparison of the performance of STI screening services for gay and bisexual men across 40 European cities: results from the European MSM Internet survey. Sex Transm Infect 2013;89:575-82 http://sti.bmj. com/content/89/7/75

6 Lowndes CM, Fenton KA, European Surveillance of STI's Network. Surveillance systems for STIs in the European Union: facing a changing epidemiology. Sex Transm Infect 2004;80:264-71.

7 Schmidt AJ, Sander D, Noori T. From HIV-testing to Gay Health Centres: A Mapping of European 'Checkpoints'. HepHIV Conference, 2017. Available: https://www. researchgate.net/publication/313441476_From_HIV-testing_to_Gay_Health_ Centres A Mapping of European_Checkpoints

8 Lorente N, Fernàndez-López L, Fuertes $R$, et al. COBA-Cohort: a prospective cohort of HIV-negative men who have sex with men, attending community-based HIV testing services in five European countries (a study protocol). BMJ Open 2016;6:e011314.

9 Ogale Y, Yeh PT, Kennedy CE, et al. Self-Collection of samples as an additional approach to deliver testing services for sexually transmitted infections: a systematic review and meta-analysis. BMJ Glob Health 2019;4:e001349.

10 The EMIS Network. EMIS-2017. The European Men-Who-Have-Sex-With-Men Internet survey. key findings from 50 countries Stockholm: European centre for disease prevention and control, 2019. Available: http://sigmaresearch.org.uk/reports/item/ report2019a

11 Weatherburn P, Hickson F, Reid DS, et al. European Men-who-have-sex-with-men Internet survey (EMIS-2017): design and methods. Sexuality Research and Social Policy 2019;28 https://doi.org/

12 Weatherburn P, Schmidt AJ, Hickson F, et al. The European Men-who-have-sex-withmen Internet survey (EMIS): design and methods. Sex Res Soc Policy 2013;10:243-57 http://link.springer.com/article/

13 European Centre for Disease Prevention and Control. Gonorrhoea. in: ECDC. annual epidemiological report for 2017. Stockholm: ECDC, 2019. Available: https://www. ecdc.europa.eu/sites/default/files/documents/gonorrhoea-annual-epidemiologicalreport-2017.pdf
14 Annan NT, Sullivan AK, Nori A, et al. Rectal chlamydia--a reservoir of undiagnosed infection in men who have sex with men. Sex Transm Infect 2009:85:176-9.

15 Clutterbuck D, Asboe D, Barber T, et al. United Kingdom national guideline on the sexual health care of men who have sex with men. Int J STD AIDS 2016;2018:956462417746897.

16 Chow EPF, Camilleri S, Ward C, et al. Duration of gonorrhoea and Chlamydia infection at the pharynx and rectum among men who have sex with men: a systematic review. Sex Health 2016:13:199-204.

17 Public Health England. Sexually transmitted infections and screening for Chlamydia in England, 2018. Health Protection Report 2019;13 https://pcwhf.co.uk/wp-content/ uploads/2019/06/hpr1919_stis-ncsp_ann18.pdf

18 Forster AS, Gilson R. Challenges to optimising uptake and delivery of a HPV vaccination programme for men who have sex with men. Hum Vaccin Immunother 2019; 15:1541-3.

19 European Centre for Disease Prevention and Control. Guidance on HPV vaccination in Eu countries: focus on boys, people living with HIV and 9-valent HPV vaccine introduction. Stockholm: ECDC, 2020. https://www.ecdc.europa.eu/sites/default/files/ documents/Guidance-on-HPV-vaccination-in-EU-countries2020-03-30.pdf

20 British HIV Association / British Association for Sexual Health and HIV. BHIVA/BASHH guidelines on the use of HIV pre-exposure prophylaxis (PreP), 2018. Available: https:// www.bhiva.org/file/5b729cd592060/2018-PrEP-Guidelines.pdf

21 Hoover KW, Butler M, Workowski K, et al. Std screening of HIV-infected MSM in HIV clinics. Sex Transm Dis 2010;37:771-6.

22 European AIDS Clinical Society. EACS guidelines 10.0. Brussels: EACS, 2019. https:// www.eacsociety.org/files/2019_guidelines-10.0_final.pdf

23 Meyer IH, Marken S, Russell ST, et al. An innovative approach to the design of a national probability sample of sexual minority adults. LGBT Health 2020;7:101-8.

24 Semlyen J, Hagger-Johnson G. Sampling frame for sexual minorities in public health research. J Public Health 2017;39:644.

25 Keane M. The Essence of the Law of Large Numbers. In: Takahashi Y, ed. Algorithms, fractals, and dynamics. Boston, MA: Springer, 1995.

26 Low N. Caution: Chlamydia surveillance data ahead. Sex Transm Infect 2008;84:80-1.

27 Vickers DM, Osgood ND. The arrested immunity hypothesis in an immunoepidemiological model of Chlamydia transmission. Theor Popul Biol 2014;93:52-62.

28 Jenness SM, Weiss KM, Goodreau SM, et al. Incidence of gonorrhea and Chlamydia following human immunodeficiency virus preexposure prophylaxis among men who have sex with men: a modeling study. Clin Infect Dis 2017;65:712-8. 